\title{
Exploring the effects of demographic transitions in Korea on migrant worker usage*
}

\author{
Nigel CALLINAN **
}

Received: December 31, 2019 Revised: January 31, 2020 Accepted: February 05, 2020

\begin{abstract}
Purpose: This study explores how demographic transitions with workforce implications taking place in South Korea are affecting the job market, and proposes a novel conceptual model to analyze the increased role that migrant workers will play as the changes progress in the medium term. Research design, data and methodology: A qualitative approach based on the available published data is used in order to create a conceptual model that could be used to determine the order in which job sector strata will be gradually taken over by migrant workers, as the demographic transitions will create an increasing need for workforce reforms. Results: The study determines that migrant workers will replace domestic Korean workers in a stratified manner, initially in rural areas, followed by regional cities and then in the industrial areas on the edges of big cities, and the strata can be analyzed based on a proposed four-category model to determine where the opportunities will open. Conclusion: It is possible to use a conceptual model for this phenomenon. Extensive Government planning is needed to avoid possible social exclusion problems and to determine how to keep the economies of rural and regional Korean cities economically viable while they are becoming increasingly depopulated.
\end{abstract}

Keywords: South Korea, Demographics, Workforce, Migration, Internationalization.

JEL Classification Code : E21, J14, K32.

\section{Introduction}

The prospect of a looming set of concurrent demographic transitions is presenting challenges for a lot of advanced high-income economies. Countries are facing sustained low fertility rates, rapid ageing and increased life expectancy trends, all taking place concurrently. These changes will all have a strong effect on workforces. However, the transitions themselves, the additional associated factors and the level of progression of the phenomena are not the same in each country, so there is no suitable one size fits all policy available to tackle the issue. One advanced country that is attempting to formulate policies to address the transitions is South Korea. Large-scale projects have been

*This work was supported by the Hannam University Research Fund

**Assistant Professor, Linton School of Global Business, Hannam University, Korea. Email: prof.callinan@hnulinton.org ๑) Copyright: Korean Distribution Science Association (KODISA)

This is an Open Access article distributed under the terms of the Creative Commons Attribution NonCommercial License (https://creativecommons.org//icenses/by-nc/4.0/) which permits unrestricted noncommercial use, distribution, and reproduction in any medium, provided the original work is properly cited. initiated by the Korean Government to explore the phenomena, and a substantial budget has been assigned in an attempt to address the changes.

Most of the published research on these demographic transitions in Korea to date, has focused on identifying the multivariate reasons behind the diminishing fertility rate, exploring measures to reduce the downward trajectory of the fertility rate, or finding a way to increase it (Bak, 2019; Yoo \& Sobotka, 2018; Mahmoudi, 2017; Stephen, 2016; Seo, 2019). This research will seek to take a novel path by building upon research by Jones (2019) that suggests that a long period of sustained low fertility with rapid ageing is now unavoidable in Korea, and plans for workforce changes and the increased usage of migrant workers now need to be made to adjust to the inevitable demographic transitions. It is important to try to get ahead of a problem as early as possible to transition from being reactive to being proactive. The only way to do this is to chart possible scenarios and then create contingency plans, and this research will attempt to contribute to this research area. 


\section{Research Question}

The aim of this paper is to explore the medium term effects of looming demographic transitions and workforce changes in South Korea upon the role and use of migrant workers, based on the available data trends. The research will seek to answer the the following question:

Can a conceptual model be created to determine the medium term availability and transfer of job opportunity sectors from domestic Korean workers to migrant workers as the current demographic transitions progress?

This research can be used as a starting point for beginning an academic conversation into the different policy initiatives that could be started to mitigate any negative social aspects of these demographic and workforce transitions.

\section{Methodology}

The methodology used in this paper is based on a qualitative synthesized literature review of the available published research. The literature review will identify a condensed, but not exhaustive, list of the major workforce trends and characteristics in Korea that are influencing the availability of roles and opportunities for migrant workers along with their trajectory. This will then be used to create a proposed model for how the stratified opportunities can be analyzed, and then the future medium term implications will be discussed.

\section{Literature Review}

\subsection{Overview}

Table 1: Interrelated Demographic Transitions

\begin{tabular}{|c|c|}
\hline Transition & Sub-Section \\
\hline $\begin{array}{c}\text { Sustained fertility rates below the } \\
\text { replacement level }\end{array}$ & 4.2 \\
\hline Increased life expectancies & 4.3 \\
\hline $\begin{array}{c}\text { High urbanization and internal } \\
\text { migration }\end{array}$ & 4.4 \\
\hline High third-level participation rates & 4.5 \\
\hline Labor mismatches & 4.6 \\
\hline $\begin{array}{c}\text { Use of migrant labor to address } \\
\text { workforce shortages }\end{array}$ & 4.7 \\
\hline A two-tier work environment & 4.8 \\
\hline $\begin{array}{c}\text { Seniority based payment and } \\
\text { workers continuing work past } \\
\text { retirement }\end{array}$ & 4.9 \\
\hline
\end{tabular}

In this research, the following set of interrelated demographic transitions will be considered from a workforce perspective. These transitions are not an exhaustive list but they are all prevalent in Korea based on the available literature, with varying levels of progress. Each of the transitions will be discussed separately in the subsections shown in Table 1.

\subsection{Sustained fertility rates below the replacement level}

The mathematical metric used by the United Nations to measure fertility is formally called the Total Fertility Rate (TFR). The TFR of a population is defined as the average number of children that would be born to a woman over her lifetime if:

She was to experience the exact current Age-Specific Fertility Rates (ASFRs) through her lifetime, and She was to survive from birth to the end of her reproductive life (Liu \& Raftery, 2018).

The TFR is calculated by summing the single-year agespecific rates at a given time. A TRT figure of approximately 2.1 per woman is referred to as replacementlevel fertility in industrialized countries, and ranges from 2.5 to 3.3 in developing countries, due to higher mortality rates (Gietel-Basten \& Scherbov, 2019). The replacementlevel figure represents the average number of children a woman would need to give birth to in order to reproduce herself, by bearing a daughter who survives to childbearing age (Hartnett, 2016). The study of fertility trends is often linked to migration studies around the world, because if replacement-level fertility levels are not sustained over a sufficiently long period, each generation will not replace itself naturally and there may be a requirement for a country to add to the working population by international migration to sustain the workforce or fund pensions (Hugo, 2017). Varying migration policies may need to be explored to see if they can mitigate the negative economic effects of sustained low TFR rates (Parsons \& Gilmour, 2018).

In the latter half of the second decade of the twenty first century, Korea's TFR dipped below 1 per women on average, which made it lower than any other country in the world (Oh, 2019). In contrast, the global average at the same time was around 2.5 children per woman, albeit with large regional variations (Alola et al., 2019). The TFR in Korea declined steadily from the 1950s onwards, from an initial figure of around 5.6 until it reached a figure below 1 (Tsuya et al., 2019). It is difficult to determine exactly when the rates will bottom out or stabilize. This kind of demographic transition, where a domestic population swells, declines and eventual stabilizes frequently occurs as 
countries get richer and the urban share of the population increases. However, the trends in Korea suggest the country could be an outlier at the extreme low end of the TFR scale meaning that the workforce disruption effects will be more profound.

\subsection{Increased Life Expectancies}

Another phenomenon that also often takes place in parallel to TFR reduction is increased life spans. As an economy develops, health care and lifestyle changes improve peoples overall wellbeing, and people usually live longer on average (although obesity trends may be pushing back on this progress in some economies). Life spans in Korea also increased quickly along these lines as the country developed. Life expectancies in Korea are now approaching the upper tier globally, although there are gender differences between men and women. According to a study published by Karacan et al (2019), women in South Korea are projected to be first globally to have an average life expectancy in excess of 90 , with a $57 \%$ confidence rate of this happening by 2030 . This information, along with the low TFR, will mean that the overall number and proportion of older people in Korea will increase, but the overall population of the country will also eventually start to decline, and this decline will accelerate quickly (Jones, 2019).

Two descriptive terms are used for countries with these kinds of demographic transitions. First, a country is described as an "aging society" when seniors account for over $7 \%$ of the population, and then a country is described as an "aged society" when seniors make up over $14 \%$ of the population (Moreira, 2016). Korea moved from being an aging to an aged society in a shorter time than it took in other advanced countries. It took Korea just 17 years for this transition to take place. In contrast, this transition took Japan 24 years, Germany 40 years and France 115 years (Kang et al., 2017). Recent United Nations Projections suggest that South Korea's population will peak at around 2024 , and then the population will start to decline quickly unless immigration policies counteract the trends, or the TFR begins to increase dramatically (Seol, 2015). This means that the population in Korea will start to move towards having a majority of women (specifically older women) based on the longer life expectancies (Moon, 2015). Based on these projections, People aged 65 years or older may account for 46.5 percent of South Korea's population by 2040 . These changes will also have a big impact on the workforce in Korea. According to these projections, Korea's workforce is likely to decline $17 \%$ between 2018 and 2040, unless the number of migrant workers admitted to Korea increases substantially.

\subsection{High urbanization and internal migration}

One more phenomenon associated with economic progress is high levels of urbanization. Korea has one of the higher urban percentages in the world at $81.5 \%$ (Kim, 2019). There was a habitual continual movement of young Korean people from the countryside to the cities initially. Then, the movement entered a second phase of young people moving from small and mid sized cities into bigger cities and to the commuter zones close to major cities, leaving rural areas and smaller cities depopulated and with a very high percentage of older people left behind. Korea has even witnessed shrinking in major cities as people move closer to Seoul and its commuter belt to access the best education and employment opportunities (Richardson $\&$ Bae, 2014). The diminishing TFR and ageing of Korean society is accelerating these trends, so the likelihood is that this phenomenon will become ever more prevalent as time passes (Fawcett, 2019). This movement of people negatively affects the supply of young workers in the depopulated areas.

\subsection{High Third Level Participation Rates}

One more feature that also has an affect on the demographic transition in Korea is third level participation rates. Korea has one of the highest levels of third level participation in the world at over $80 \%$, and most of these students' study 3 or 4-year undergraduate degrees (Jun \& Evans, 2019). In addition, Korea has a very high proportion of private universities compared to national universities and a high proportion of the private universities are in or near Seoul (Kim et al., 2019). There is a clear hierarchy when it comes to college acceptance in Korea and the university entrance process is very competitive for high-ranking universities. The majority of the more prestigious universities are in the Seoul region and the surrounding areas, so the majority of young people in Korea aspire to first move into an urban center for study preferably near or in Seoul, and then they hope to stay there to work and raise families.

In addition there are small, private, after school, exampreparation tutoring schools called Hagwons that prepare students for university acceptance processes. The most successful Hagwons are also located in Seoul and the surrounding areas. This means that families seek to locate themselves close to these Hagwons to get an advantage in the university acceptance process. Sometimes families even live separately, with one parent working elsewhere, but another parent living with the children in Seoul just to maintain access to these specialized Hagwons. So, both the university hierarchy and Hagwon system further fuel internal city-to-city and countryside to city migration in 
Korea. This is another factor pushing up the average age of the remaining population of rural areas and regional cities, creating a further need for migrant workers to address labor shortages.

\subsection{High Third Level Participation Rates}

The high level of third level participation in Korea has also contributed to a labor mismatch. Korea is still highly dependent on manufacturing and assembling products for export, but most young Korean university graduates now aspire to work in an office or in a Government role as it offers stability, good pay and comfortable working conditions (Hur, 2018). This has resulted in a big labor mismatch where there is a shortage of people in unskilled and semi-skilled jobs and a major oversupply of people seeking white-collar office jobs (Lim, 2016). One metric used to analyze the labor mismatch is the number of graduates described as being Not in Employment, Education or Training (NEET). In the under 30-age category, 21.2 percent of young Korean people were considered to be NEET in 2017, almost double the OECD average of 13.4 percent (Kwon, 2019). Meanwhile, the Korean Government approved over 56,000 work permits for migrant laborers to address labor shortages in rural and industrial areas. This suggests that the NEET category of people in Korea are not willing to take the available jobs due to the location, pay, working conditions and/or the social status of the roles. Instead, those in the NEET category keep applying for their desired office jobs until they get the one that matches their expectations.

There seems to be no evidence that increasing the payment level for non-office jobs would lead to those in the NEET category changing their expectations and taking up these jobs (Kim, 2019). If such a figure exists, it is well in excess of what would be considered a competitive salary for most of the available roles and this would not be sustainable or acceptable for the profit margin of most Korean business owners. Based on current projections, South Korea's skilled workers (i.e university degree holders) are projected to increase 26 percent by 2040 , South Korea's unskilled workers are projected to fall 51 percent by 2040 . This is likely to be the world's most rapid decline of unskilled workers, meaning that the labor mismatch is likely to continue to accelerate and workforce shortages will be widespread in rural and regional cities.

\subsection{Use of Migrant Labor to address workforce shortages}

Korea had to open up to bringing in workers from other countries to fill the open unskilled positions. The work permit system for non-nationals working in unskilled positions in Korea is called the Employment Permit System (EPS). This is combined with one of various visas (usually the E-9 visa) to provide permission to work in Korea (Kim \& Koo, 2018). The Korean Government maintains a list of countries that are eligible for EPS work permits and an annual quota of workers is maintained for each country (Abella \& Kouba, 2016). If there are any legal or administrative problems with people from a certain country their quotas can simply be reduced as needed during the next year. There is a general time limit placed on EPS work in Korea. Workers are allowed to work a maximum of 4 years and 10 months and then they must leave the country (Choi, 2018). There is a mechanism for allowing some workers to get a second EPS period of 4 years and 10 months if they fall into the Well Behaved work category (Torneo, 2016). Korea also has a visa (called the H-2) for people of Korean ancestry to work in Korea temporarily. The people that fall into this category are mostly from China and Russia. For those on migrant worker visas, there is a path to permanent residency but as it is a points-based system that includes minimum education and income thresholds, not many of the unskilled workers can take steps towards permanent residency in Korea (Chung, 2018).

The demand for migrant workers in Korea is high and some employers continue to employ these workers even after their permitted visas and work permits are finished. These workers are described as over stayers and they are growing issue in Korea. In 2017, the number of over stayers in Korea was estimated to be over 200,000, which would be close to $10 \%$ of the total number of migrant workers in the country (Callinan, 2019). The Government's legal penalties for employers that give jobs to people who are overstaying and the enforcement and investigations into these employers often are not enough of a deterrent to dissuade employers from taking the risk of employing these workers illegally (Kim, 2019). Moreover, as mentioned earlier a lot of these jobs are in rural areas and mid sized regional cities so it can be challenging to police it effectively. This problem seems likely to grow unless the Korean Government loosens the EPS work permit system quotas limits to match the growing demand for migrant workers.

\subsection{Two-tier working environment}

Another feature of Korea's working environment is a two-tier working system. Roles for domestic workers are split into regular (i.e permanent) and non-regular (i.e contract roles). Under Korean law, the bar required to fire workers is extremely high so regular jobs are highly coveted (Kim \& Song, 2019). In addition, regular jobs often have higher compensation and benefits than nonregular jobs. Non-regular jobs can usually last a maximum of three years before automatically becoming regular jobs 
so most companies employ people on two one-year contracts before letting them go, in order to avoid them becoming regular staff and achieving the higher legal status (Arita et al., 2019). As Korea has a big gender equality gap, this means that the majority of Korean women in the workforce fall into the lower paid non-regular working category.

\subsection{Seniority based payment and workers continuing work past retirement}

Koreas traditional pay structures are based on seniority, which means that older and more experienced workers get paid gradually more and more until they retire. However, as an increasing amount of roles have higher technical competency expectations and older members of the workforce often have lower technical competency, it means that the highest paid workers sometimes have relatively low productivity. This has led to Korean companies strongly encouraging workers to retire early to save on staffing overheads. These retired workers are often in their late $40 \mathrm{~s}$ or $50 \mathrm{~s}$, so they frequently try to start businesses or reenter the workforce after their forced retirements (Shin, 2019). However, they sometimes have to accept lesser roles if they reenter the workforce. This results in a loss of income that eventually means that Korean workers frequently work past the legal retirement age in diminished roles to continue getting an income (Park, 2019).

The workforce situation and gender inequality, combined with low state pensions and social welfare means that Korea now has an elderly poverty problem. As explained earlier, the older generation has more women than men due to life expectancy differences, and Korea has strong gender inequality, so the people suffering from elder poverty are disproportionality older women and more specifically older women living in rural areas (Mansury \& Baek, 2019). This trend seems likely to also accelerate and become more widespread based on current projections.

\subsection{Seniority based payment and workers continuing work past retirement}

In summary, a large array of demographic transitions is taking place in Korea concurrently, and the rate of change is very high. These demographic shifts are interrelated and they all affect the workforce, so it is hard to study one in isolation without including a consideration of the others. The interdependence of the shifts means that the overall trends are extremely hard to reverse. This is why a consideration of the effects of changes and scenario planning is essential.

\section{Analysis}

\subsection{Overview}

As the domestic working age population in Korea dwindles, more and more sectors are likely to have jobs that will need to be gradually filled by non-Korean workers. This will take place based on a combination of supply and demand factors, but the transition will be staggered. Jobs are highly to be taken over by migrant workers in a stratified way, sector by sector. The first sector that was taken over on a large scale by migrant workers was Small to Medium Enterprise (SME) manufacturing (Choi, 2019). The reason it was limited to SME manufacturing only was that the Korean Government restricted the ability of large corporations to sponsor EPS work permits and visas to nonKorean nationals, as large corporation jobs were highly paid and protected for domestic Korean workers. This will be discussed below in section 5.2. The analysis will be based on four main proposed stratification categories shown below in Fig.1. Each of the factors will be discussed separately in the subsections that follow.

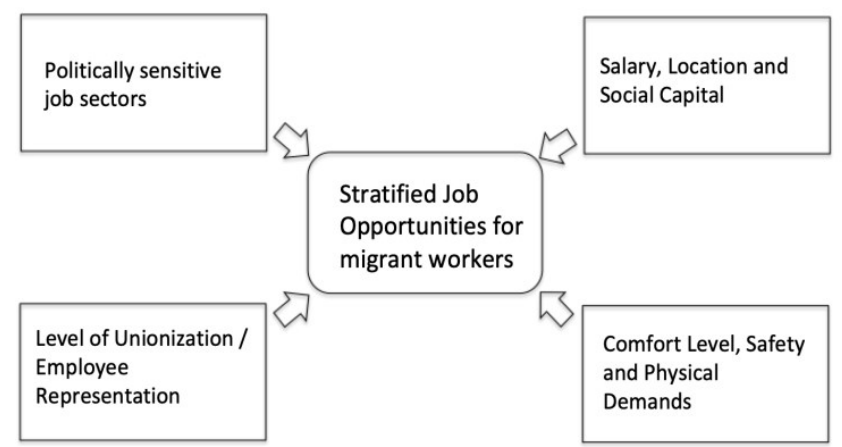

Figure 1: Job Opportunity Stratification Conceptual Model

\subsection{Politically sensitive job sectors}

Korea has a group of mostly family-run companies called Chaebol. Examples of Chaebol include Samsung, Hyundai, SK and Lotte. These companies were the engines of growth behind Korea's fast development throughout the 1970s and 1980 s, and they continue to play a pivotal role in the economy (Ducret \& Isakov, 2019). There is a strong connection between the national pride of Korea and the success of these companies, especially for older generations (Uttam, 2019). Therefore, the relationship between the Government, their workforces and the leadership of these companies is very politically sensitive in Korea. If these big companies were perceived to be replacing domestic Korean workers with migrant workers for their operations inside Korea to reduce costs, it could become a national-level 
political issue and there is a high possibility that public protests would occur (Roh \& Brewster, 2018).

Parents and grandparents traditionally saw getting a job at one of these companies as the highest possible achievement for their children and some even saw it as something they were entitled to expect as part of an unwritten social contract (Kang, 2018). The unwritten contract was that workers would work hard with extremely long hours for the Chaebol companies, but in return the company should pay high salaries, provide stable and safe jobs and take care of their workers. The large Chaebol companies frequently outsource certain operations to smaller companies, and these operations are sometimes staffed by migrant workers without any political reaction (Cho et al., 2018). However, the prestigious jobs working directly with the Chaebol, especially the regular (i.e permanent) jobs, are unlikely to be made available to migrant workers in the medium term at least, so this protected strata will remain in place and will continue to be inaccessible to migrant workers.

\subsection{The salary, location and social status level of the job}

As Korea is still mostly a monolingual and mono cultural country, the workplace practices and working language within Korean organizations is identifiably Korean, and the medium of work communication is Korean in most scenarios. This means that unless there is another skillset in demand for the job (e.g language skills or local knowledge of another country), the most attractive and convenient candidates to hire will be locals even before considering visa and work permit complications (Kim, 2019). However, there are always supply and demand considerations involved when hiring workers. Companies need to find competent workers at the lowest possible prices to minimize their overheads. If a company cannot afford, or is not willing to pay the market price demanded by domestic workers, or are located in an area without a supply of local workers, they may employ migrant workers (Yang \& Horak, 2019).

As seen earlier, Korea has a skills mismatch and the high proportion of Korean young people who go through third level education have elevated payment expectations. They also have the expectation that a University degree will lead the way to a regular job in an office environment. Thus, there are some lower paid jobs that young Korean people will do temporarily. There is even a word for these types of temporary jobs in Korea. They are called "arbeit" jobs. This uses a German word but changes the meaning to describe temporary jobs associated with university students working part time while studying (Lim \& Lee, 2019), university students working during their vacation, or jobs that students do while they are preparing exams or do interviews for office roles. Some types of jobs included under this umbrella would include fast food restaurant jobs, waiting tables, working in coffee shops, cinema attendants, and other basic service jobs. These jobs are usually paid at minimum wage or slightly above minimum wage (Sohn, 2019). As students and recent graduates often depend on these jobs for survival and the pay is low, these "arbeit" jobs in urban areas near universities will continue to be dominated by students, and will not be taken over by migrant workers in the foreseeable future (but some of the jobs may be wiped out by automation of course).

As explained earlier, the social status of an office job is very important in Korea. Even entry-level office jobs are seen as a stepping-stone towards building up a resume and getting a coveted regular job (Clifford, 2016). As the competition is high due to the over supply of third level graduates, companies are able to turn some of their entry level jobs into very low paid internship positions and hire recent or pending graduates. These internship jobs will also not be taken by migrant workers, as the salaries are already too low to make it advantageous to business owners to hire migrant workers. So, the office worker strata will not move over to migrant workers in the medium term.

\subsection{The level of unionization or employee representation}

Korea has strong union representation in certain sectors although the overall union participation rate of Korean workers is relatively low at around $10 \%$ (ILO, 2019). As with most unions around the world, Korean unions use collective bargaining techniques to negotiate for higher salaries and better conditions (Shin et al., 2019). Part of their protective approach would be to ensure that their jobs cannot be replaced by lower paid migrant workers or outsourced to contractors. If any moves to make this happen take place, the unions would immediately take industrial action including strikes or protests (Kim \& Cook, 2018). This means that roles with union representation will also not be available to migrant laborers unless there are no Korea laborers left who are willing to take those jobs.

\subsection{The comfort level, safety and physical demands of the job}

As mentioned earlier, Korea has a phenomenon where some seniors have to keep working beyond the legal requirement age (Choi, 2016). This means that there are certain sectors and roles that are dominated by seniors. Seniors often vote with high turnout rates in Korea. This means that the Korean Government cannot make policies 
that negatively affect the older population and hope to be reelected.

An example of a comfortable unskilled job that the Korean domestic workers will seek to keep control of is professional driving. As explained earlier, Korean workers are frequently forced to retire early from white-collar office jobs and sometimes they then become taxi or bus drivers. When any changes or even technology innovations threaten bus or taxi drivers in Korea, it triggers large scale protests that can shut down entire cities (Hong et al., 2015). This means that allowing non-Korean workers to enter the workforce and compete for those jobs is politically impossible currently. So, it is likely that this working area will stay as one where Korean workers exclusively work and no EPS work permits are issued for until the jobs disappear due to self driving vehicle technology (which will also meet with strong protests when it is ready for implementation).

Another example of a comfortable unskilled job is apartment maintenance / security guards. Large apartment complexes in Korea often have a number of maintenance /security staff members (Park et al., 2018). Often they are post legal retirement age workers who previous worked in other professions. The workers would fall into the same category as taxi drivers, except they don't have as much collective representation. However, this role is also likely to be automated by technology before it ever becomes a role that the Government allows EPS permits and work visas to be sponsored for. So, these strata of jobs will also remain with Korean workers in the medium term.

\subsection{Implications and Recommendations}

In most countries, immigration rates are highest into urban areas and larger cities. For example, the big cities in the U.S like New York and L.A are often described as melting pots because they have high diversity and new people arrive from all over the world every day. However, in Korea different migration and diversification trends are taking place.

As shown in sections 5.2 to 5.5 , there are still a high number of stratified roles that will still not be available to migrant workers for a variety of reasons. Most of these unavailable positions are located in the commercial centers and commuter zones of the major urban cities of Korea. This means that most of the migrant workers will be taking jobs in rural areas, and in the small regional cities, and on the outskirts of cities in the industrial areas.

In these countryside and regional cities, the proportion of older Korea people is the highest. The fertility rates are not much lower than urban areas, but the younger Korean people tend to leave rural areas and regional cities, and then move to the biggest urban areas to study and work if they can. This means that rural areas and regional cities have the biggest workforce shortages, and this trend will continue and even accelerate as the demographic transitions take hold. So, farming, fishing and other rural industries will need to be almost completely staffed by non-Korean laborers, who will also live in these rural areas. Factory jobs in small to medium sized enterprises in regional cities will also be taken over by migrant workers. As the majority of workers will continue to be working in Korea on temporary EPS work permits, they will be often housed in dormitories provided by their jobs, or else in low budget rooms. Also, as these laborers will usually remit their earnings and they are unlikely to bring their families to Korea while they are on temporary work visas, the demographic composition of these areas will be a mix of an older diminishing Korean population, and unskilled, working-age temporary migrant workers. Due to language, age and cultural barriers, there may not be a lot of interaction and integration between these two dominant groups.

Due to the labor shortages, some of the migrant workers will become supervisors and move up to middle management roles but they will be blocked from the higherlevel roles and ownership of businesses unless the availability of domestic Korean workers is completely wiped out. As they will be working in Korea on limited temporary visas, these migrant workers will rarely start new businesses. Also, their consumption habits will be based on sustenance because they will be sending their money home by remittance. If they do start businesses, it will tend to be in their own country using the capital they are sending from Korea, with extended family members as the initial employees. This means that the retail, leisure and other commercial activities of these rural areas will diminish, and only basic functional businesses will continue. Also, rural and regional city housing prices will collapse, and vacant housing stock will increase dramatically as older Korean people die without anyone to replace them. In order to avoid major depopulation of these areas, the Government should consider buying or repurposing vacant housing for use as social housing. The Korean Government could try to turn these rural areas into retirement villages and provide incentives for retirees to pass on their urban housing to children early with reduced capital gains or inheritance taxes. This would reduce house price inflation in high demand urban neighborhoods, and possibly slow down population loss in rural areas.

Korea is a highly urbanized country and demand is high for housing in densely populated areas associated with better education opportunities, commercial area and transport links. So, it would usually not be possible for many non-Korean workers to move into these areas, as the housing costs and deposits required to live here are often 
prohibitive without access to financing, and that would require a longer credit history than most non-national temporary workers can provide to Korean banks.

This means there will be a relatively low level of integration and mixing between the younger urban Koreans in major cities and the migrant workers in the smaller cities and rural areas. This will be accentuated by the fact that the migrant workers will be transient due to the nature of their work permits and visas. So, Korea will increasingly see areas of regional cities and the countryside where migrant workers live alongside older Korean people in large and increasing numbers.

\section{Conclusion}

\subsection{Implications and Recommendations}

This research aimed to explore the varied demographic transitions that are underway in Korea and how they will affect the use and role of migrant workers. The research started off with a literature review and then in the analysis section, the stratified factors that will affect opportunities for migrant laborers were proposed and discussed as a conceptual model.

\subsection{Key takeaway of the study}

The study suggests that in the medium term, Korea will most likely end up with a mix of diverse young transient migrant workers in rural and regional cities living alongside elderly Korean people (the majority of whom will be low income or retired, poor and female), while young and affluent Korean individuals and families will continue to live in the major cities with relatively low levels of diversity. This will pose a major challenge for social integration and a lot of work will have to be done to avoid social conflict. The study concludes that migrant workers will take over opportunities in a stratified way, and the trajectory of available sectors can be explored using the below conceptual model.

Politically sensitive job sectors.

The salary, location and social capital level of the job. The level of unionization or employee representation. The comfort level, safety and physical demands of the job.

\subsection{Considerations}

The most likely outcome is a non-integrated transient migrant workforce that could cause some social problems and resentment. Korea will most likely become a country where the lifestyles, living standards and demographics diverse hugely between large urban areas and rural and regional cities. Leaving Seoul and other major cities will soon be like travelling to another country for many. It may even result in people not wanting to leave the city often and perceptions may grow that rural and smaller regional cities are dangerous due to xenophobia.

\subsection{Limitations and Further Study Options}

There are some limitations to this study. It covers a wide range of trends so perhaps some key trends have not been included. For example, no consideration was made of the role of international marriages in rural and regional cities for example. Also, the possibility of reunification with North Korea and the possible supply of labor from that channel was not considered. This could have a big influence on the future supple of labor in South Korea.

There is a wide range of further research options available on this topic. Perceptions of these changes could be determined using surveys and other measures. Policy and planning could be analyzed to assess readiness and preparation. Suggestions for reform of the EPS and work visa system could also be explored in further research. Awareness of the oncoming demographic changes would also be an interesting study area. It is covered in the news from a numerical perspective but awareness of the social implications may not be widespread.

\section{References}

Abella, M., \& Kouba, S. (2016). Structures for the governance of labor immigration in Japan, the Republic of Korea, and Singapore. Labor Migration in Asia, 24(3) 8-14.

Alola, A. A., Bekun, F. V., \& Sarkodie, S. A. (2019). Dynamic impact of trade policy, economic growth, fertility rate, renewable and non-renewable energy consumption on ecological footprint in Europe. Science of the Total Environment, 685(1), 702-709.

Arita, S., Nagayoshi, K., Taki, H., Kanbayashi, H., Takenoshita, H., \& Yoshida, T. (2019). Legitimation of Income Inequality in Japan: A Comparison with South Korea and the United States. Discussion Paper Series. Centre for French-Japanese Advanced Studies in Paris. Retrieved Nov 22, 2019 from https://hal.archives-ouvertes.fr/hal-02160502

Bak, H. (2019). Low Fertility in South Korea: Causes, Consequences, and Policy Responses. Global Encyclopedia of Public Administration, Public Policy, and Governance. Springer, Cham. 21(4), 235-242.

Callinan, N. (2019). Can examples of the Japanese "Galapagos Effect" theory be identified among South Korean High-Tech Service Companies? The East Asian Journal of Business Management (EAJBM), 9(2), 17-25.

Cho, M. H., Bae, J., \& Chung, J. (2018). Competitive strategy and challenges for the chaebol. Strategic, Policy and Social 
Innovation for a Post-Industrial Korea. Routledge, 58-67.

Choi, E. (2016). Older Workers and Federal Work Programs: The Korean Senior Employment Program (KSEP). Journal of aging \& social policy, 28(4), 308-324.

Choi, S. (2019). Governing through support: Migrant women's affective labor and government services for migrant workers in South Korea. Asian Journal of Women's Studies, 25(3), 352374.

Choi, Y. C. (2018). Legislation and Policies for The Employment of Foreign Worker in Korea. Sociological Jurisprudence Journal, 1(2), 74-81.

Chung, E. A. (2018). Creating hierarchies of noncitizens: race, gender, and visa categories in South Korea. Journal of Ethnic and Migration Studies, 3(4) 1-18.

Clifford, M. L. (2016). Troubled tiger: Businessmen, bureaucrats and generals in South Korea. Routledge, 115-119

Ducret, R., \& Isakov, D. (2019). The Korea discount and chaebols. Université de Fribourg. 224-235.

Fawcett, James T. (2019). Urbanization, Migration. Women In The Cities Of Asia: Migration And Urban Adaptation, 1-9.

Gietel-Basten, S., \& Scherbov, S. (2019). Exploring the 'True Value' of Replacement Rate Fertility. Population Research and Policy Review, 1(4) 1-10.

Hartnett, C. S. (2016). Fertility Rates. Encyclopedia of Family Studies, 1, 1-5.

Hong, K., Lee, K. M., \& Jang, S. N. (2015). Incidence and related factors of traffic accidents among the older population in a rapidly aging society. Archives of gerontology and geriatrics, $60(3), 471-477$

Hugo, G. (2017). Asia's international migration. Routledge Handbook of Asian Demography. Routledge, 310-330

Hur, J. J. (2018). Changes in the Korean labor market. The Evolution of Korean Industrial and Employment Relations, 1, 167.

ILO (2019). Industrial Relations Participation Report. International Labor Organization. 44

Jones, G. W. (2019). Ultra-low fertility in East Asia: policy responses and challenges. Asian Population Studies, 15(2), 131-149.

Jun, S. K., \& Evans, K. (2019). Third Age Education and the Senior University Movement in South Korea. The University of the Third Age and Active Ageing. Springer, Cham, 219-231.

Kang, L., Lee, B. H., \& Choi, K. S. (2017). A study on innovation system approach to national R\&D in the aged society: focusing on GT in Korea. International Information Institute (Tokyo). 20(12), 8381-8392.

Kang, S. D. (2018). Democracy Without Workers: The "Work Society" in Korea After Democratization. The Quality of Democracy in Korea. Palgrave Macmillan, Cham, 207-236

Karacan, I., Sennaroglu, B., \& Vayvay, O. (2019). Analysis of life expectancy across countries using decision tree. East Mediterr Health J, 20(14), 25.

Kim, B. K., Hwang, H., Cho, H. J., \& Jang, Y. S. (2019). The Rationalization of Korean Universities. Minerva, 1, 1-21.

Kim, D. B., \& Cooke, F. L. (2018). The evolution of HRM practices and labor unions. The Evolution of Korean Industrial and Employment Relations, Edward Elgar Publishing, 101-124.

Kim, J. (2019). 'Ethnic capital' and 'flexible citizenship' in unfavourable legal contexts: stepwise migration of the Korean Chinese within and beyond northeast Asia. Journal of Ethnic and Migration Studies, 45(6), 939-957.

Kim, J. J, (2019). A Study on the Retirement Satisfaction according to the General Characteristics of Retired Elderly. International Journal of Industrial Distribution \& Business, 10(12), 25-34.

Kim, J., \& Song, M. (2019). Labor-Management Council in Korea: A Look at the Past, Contemporary Trends, and Challenges for the Future. The Palgrave Handbook of Workers' Participation at Plant Level. Palgrave Macmillan, New York, 437-458.

Kim, S. Y. (2019). Migrant Laborers in South Korean Local Communities: Making Them Work More Decently. Lex Localis-Journal of Local Self-Government, 17(1), 54-62.

Kim, S. J. (2019). Productivity of cities. Routledge. 220-227.

Kim, S., \& Koo, J. W. (2016). Securitising, Economising and Humanising Immigration: The Case of the Employment Permit System in South Korea. Asian Studies Review, 40(4), 619-635.

Kwon, O. Y. (2019). Social trust in labour and its socioeconomic effects in Korea. Social Trust and Economic Development. Edward Elgar Publishing, 139-147.

Lim, J. (2016). Labor Market Distortion with Discouraged Worker Effects in Korea. Quantitative Regional Economic and Environmental Analysis for Sustainability in Korea. Springer, Singapore, 45-66.

Lim, J. Y., \& Lee, Y. M. (2019). Exit duration and unemployment determinants for Korean graduates. Journal for Labour Market Research, 53(1), 5-12.

Liu, P., \& Raftery, A. E. (2018). Accounting for Uncertainty About Past Values In Probabilistic Projections of the Total Fertility Rate for All Countries. Technical Report no. 648. Department of Statistics University of Washington, 1-14

Mahmoudi, K. M. (2017). Rapid Decline of Fertility Rate in South Korea: Causes and Consequences. Open Journal of Social Sciences, 5(07), 42-49.

Mansury, Y., \& Baek, K. H. (2019). Gender inequality among urban households in South Korea. Regional Science Policy \& Practice, 11(1), 23-38.

Moon, K. H. (2015). South Korea's demographic changes and their political impact. East Asia Policy Paper, 6(10), 1-7.

Moreira, T. (2016). Science, technology and the ageing society. Routledge. 54-61

Nakagaki, Y. (2019). Convex relationship between fertility and gender gap. Economics Bulletin, 39(3), 2014-2026.

Oh, J. (2019). Forecast and identifying factors on a double dip fertility rate for Korea. The Korean Journal of Applied Statistics, 32(4), 463-483.

Park, H., Hwangbo, Y., \& Nam, Y. (2018). The Effect of Employment and Occupational Factors on Late-Life Depression in Korea. Journal of Occupational and Environmental Medicine, 60(9), 492-497.

Park, S. M. (2019). Effects of work conditions on suicidal ideation among middle-aged adults in South Korea. International Journal of Social Psychiatry, 65(2), 144-150.

Parsons, A. J., \& Gilmour, S. (2018). An evaluation of fertility-and migration-based policy responses to Japan's ageing population. PloS one, 13(12), 14-21.

Richardson, H. W., \& Bae, C. H. C. (2014). Shrinking cities in 
South Korea: The future. In Shrinking Cities. Routledge, 138151.

Seo, S. H. (2019). Low fertility trend in the Republic of Korea and the problems of its family and demographic policy implementation. Population and Economics, 3(1), 29-35.

Seol, D. H. (2015). Population Ageing and International Migration Policy in South Korea. Economy and Society, 106(1), 73-114.

Shin, I., Park, S., Cho, S. P., \& Choi, S. (2019). The effect of labor unions on innovation and market valuation in business group affiliations: new evidence from South Korea. Asian Business \& Management, 13(2) 1-32.

Shin, K. Y. (2019). Neo-Liberal Economic Reform, Social Change, and Inequality in the Post-Crisis Period in South Korea. Asiatische Studien-Études Asiatiques, 73(1), 89-109.

Sohn, I. (2019). The Contentious Politics of Youth Unemployment: Comparing Korea and Taiwan. The Korean Journal of International Studies. 17(1), 55-77.

Stephen, E. H. (2016). Korean unification: a solution to the challenges of an increasingly elderly population?.Asian Population Studies, 12(1), 50-67.

Torneo, A. R. (2016). Immigration policies and the factors of migration from developing countries to South Korea: An empirical analysis. International Migration, 54(3), 139-158.

Tsuya, N. O., Choe, M. K., \& Wang, F. (2019). Paths to Low Fertility. Convergence to Very Low Fertility in East Asia: Processes, Causes, and Implications. Springer, Tokyo, 17-28.

Uttam, J. (2019). Beyond Neo-liberalism: Analyzing the 'PostDevelopmental State' in South Korea. International Studies, 56(4), 236-254.

Yang, I., \& Horak, S. (2019). Formal and informal practices in contemporary Korean management. The International Journal of Human Resource Management, 30(22), 3113-3137.

Yoo, S. H., \& Sobotka, T. (2018). Ultra-low fertility in South Korea: The role of the tempo effect. Demographic Research, $38(1), 549-576$. 